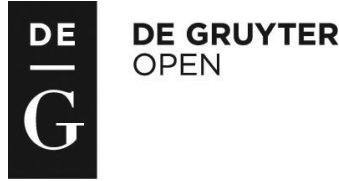

\section{POLYPHENOLS IN MONOGASTRIC NUTRITION - A REVIEW}

\author{
Krzysztof Lipiński, Magdalena Mazur, Zofia Antoszkiewicz, Cezary Purwin \\ Department of Animal Nutrition and Feed Science, \\ University of Warmia and Mazury, Oczapowskiego 5, 10-719 Olsztyn, Poland \\ •Corresponding author: krzysztof.lipinski@uwm.edu.pl
}

\begin{abstract}
The popularity of plant-based feed additives in livestock production has increased significantly in the last decade. Polyphenols are secondary plant metabolites which contain bioactive components and deliver positive effects for humans and animals. They are renowned for their anti-inflammatory, immunomodulatory and anti-mutagenic effects. Polyphenols have antioxidant properties, and they minimize the negative consequences of oxidative stress. Their antioxidant capacity is comparable to that of the major biological antioxidants: vitamins $\mathbf{E}$ and $\mathrm{C}$. Despite those advantages, polyphenols are characterized by low bioavailability, and further research is needed to harness their full potential in livestock farming. This article presents a review of findings from recent studies investigating the efficacy of polyphenols in monogastric nutrition, with special emphasis on their antioxidant properties.
\end{abstract}

Key words: polyphenols, immunomodulatory effect, growth performance, gut health, antioxidant activity

Consumer awareness about the health properties, safety and quality of food products of animal origin has increased the popularity of natural supplements in livestock production. In January 2006, the European Union banned the use of antibiotic growth promoters in animal feeds, which shifted the producers' attention to plant-based supplements. Herbs, essential oils, spices, plant extracts and phytobiotics deliver a host of health benefits for animals; they improve animal performance and the quality of the resulting animal products. Plant-based supplements and their secondary metabolites are alternative natural growth promoters that are widely used in livestock farming (Wallace et al., 2010; Hashemi and Davoodi, 2011; Yesilbag et al., 2011).

Phytochemicals that occur naturally in plants attract special interest. This group of compounds includes polyphenols, secondary plant metabolites which are a common component of human and animal diets (Petti and Scully, 2009; Chiva-Blanch 
and Visoli, 2012; Paszkiewicz et al., 2012). Polyphenols are present in vegetables, fruit, cereals, chocolate and beverages such as wine, coffee, black tea and green tea (D’Archivio et al., 2007; Landete, 2013). They occur in various parts of plants, including roots, leaves, flowers, fruit and seeds, and they protect plants against pests and UV radiation (Scalbert et al., 2002; Petti and Scully, 2009). Polyphenols also act as plant hormones, inhibitors of enzymatic reactions and plant growth regulators (Majewska and Czeczot, 2009).

Polyphenols contain active ingredients, they exert non-specific effects on living organisms, and regulate the activity of enzymes and cell receptors (D'Archivio et al., 2007). They have anti-inflammatory, anti-allergic, immunomodulatory and anti-mutagenic activities. Most importantly, polyphenols are powerful antioxidants that prevent oxidative stress and reduce the risk of cancer, neurodegenerative and cardiovascular diseases (Scalbert et al., 2005; Petti and Scully, 2009; Paszkiewicz et al., 2012). Despite those benefits, most polyphenols are not readily absorbed in the small intestine, and they accumulate in small quantities in bodily tissues (Manach et al., 2004; Surai, 2014). For this reason, further research is needed to explore the use and functional roles of those compounds in human and animal diets. This article presents a review of findings from recent studies investigating the efficacy of polyphenols in monogastric nutrition, with special emphasis on their antioxidant properties.

\section{Classification, structure and metabolism of polyphenols}

Around 8,000 polyphenolic compounds with varied and complex chemical structure have been identified in different plant species. Polyphenols can be divided into two main groups, flavonoids and non-flavonoids, based on the number of aromatic rings and their binding affinity for different compounds (Fraga et al., 2010; Surai, 2014).

Flavonoids are the largest group of polyphenols which can be further divided into six subclasses: anthocyanins, isoflavones, flavanones, flavonols, flavones and flavanols (D'Archivio et al., 2007; Surai, 2014). Flavonoids are composed of two benzene rings connected through a three-carbon bridge, which form the C6-C3-C6 structural backbone (Jasiński et al., 2009; Fraga et al., 2010). In plants, flavonoids occur together with sugar residues as glycosides or in free form as aglycones. Individual compounds are classified based on different ring substituents created during hydroxylation, methylation, glycosidation and acylation (D'Archivio et al., 2007; Jasiński et al., 2009; Majewska and Czeczot, 2009). Flavonoids are responsible for red, blue and yellow coloration of plants. They are found mainly in onions, leeks, soybeans, berries and tea (Jasiński et al., 2009; Majewska and Czeczot, 2009; Landete, 2013).

Non-flavonoids contain at least one aromatic ring which is linked to one or more hydroxyl groups. Non-flavonoids include phenolic acids, lignans and stilbenes (Surai, 2014). Phenolic acids are further subdivided into two groups of cinnamic acid derivatives and benzoic acid derivatives. They are present in coffee, grapes and red wine (D'Archivio et al., 2007; Han et al., 2007). The classification and sources of polyphenolic compounds are presented in Table 1. 
Table 1. Classification and sources of selected polyphenolic compounds (Han et al., 2007; Zalega and Szostak-Węgierek, 2013; Myburgh, 2014; Surai, 2014)

\begin{tabular}{|c|c|c|c|}
\hline Group & $\begin{array}{l}\text { Polyphenolic } \\
\text { compounds }\end{array}$ & $\begin{array}{l}\text { Examples } \\
\text { of compounds }\end{array}$ & Source \\
\hline \multirow[t]{6}{*}{ Flavonoids } & anthocyanins & $\begin{array}{l}\text { cyanidin, } \\
\text { pelargonidin, } \\
\text { delphinidin, etc. }\end{array}$ & $\begin{array}{l}\text { black currant, elderberry fruit, blackberries, } \\
\text { cherries, strawberries, raspberries, chokeberry }\end{array}$ \\
\hline & isoflavones & $\begin{array}{l}\text { genistein, } \\
\text { daidzein, } \\
\text { equol, etc. }\end{array}$ & soybean and its products, peas, lentils, grapes \\
\hline & flavanones & $\begin{array}{l}\text { naringenin, } \\
\text { hesperetin, } \\
\text { eriodictyol, etc. }\end{array}$ & grapefruit, oranges, tangerines, peppermint \\
\hline & flavonols & $\begin{array}{l}\text { quercetin, } \\
\text { kaempferol, } \\
\text { isorhamnetin, etc. }\end{array}$ & $\begin{array}{l}\text { onions, broccoli, black tea, lettuce, apples, dill } \\
\text { weed }\end{array}$ \\
\hline & flavones & $\begin{array}{l}\text { apigenin, } \\
\text { luteolin, } \\
\text { diosmin }\end{array}$ & $\begin{array}{l}\text { celery, parsley, red pepper, lemon, oregano, } \\
\text { rosemary }\end{array}$ \\
\hline & flavanols & $\begin{array}{l}\text { catechin, } \\
\text { epicatechin, } \\
\text { epigallocatechin }\end{array}$ & $\begin{array}{l}\text { tea, grapes, red wine, apples, blackberries, } \\
\text { apricots, dark chocolate }\end{array}$ \\
\hline \multirow[t]{3}{*}{ Non-flavonoids } & $\begin{array}{l}\text { phenolic } \\
\text { acids }\end{array}$ & $\begin{array}{l}\text { caffeic acid, } \\
\text { chlorogenic acid, } \\
\text { ferulic acid }\end{array}$ & $\begin{array}{l}\text { coffee, olives, cabbage, apples, cherries, } \\
\text { tomatoes, pears, asparagus }\end{array}$ \\
\hline & lignans & $\begin{array}{l}\text { pinoresinol, } \\
\text { podophyllotoxin, } \\
\text { steganacin }\end{array}$ & linseed, sesame seeds, chives, nuts \\
\hline & stilbenes & resveratrol & $\begin{array}{l}\text { red wine, red grapes, peanuts, blueberries, } \\
\text { raspberries }\end{array}$ \\
\hline
\end{tabular}

The metabolism of polyphenols has not been fully elucidated. According to estimates, only approximately $5-10 \%$ of polyphenols are absorbed and metabolized in biochemical pathways (Chiva-Blanch and Visioli, 2012). Aglycones, non-sugar hydrophobic components of glycosides, are absorbed by passive diffusion in the small intestine (Manach et al., 2004; Majewska and Czeczot, 2009). Polyphenols are glucuronidated and sulfated inside enterocytes. Those metabolites are transported from the intestine to the serous membrane by glucuronyl transferase or sulfotransferase (Teng et al., 2012). Other polyphenols occur in foods as hydrophilic glycosides, esters and polymers of higher molecular weight, which are broken down by intestinal bacterial enzymes (mainly $\beta$-glucosidases) to aglycone and sugar, and are absorbed only in the large intestine (Majewska and Czeczot, 2009). Compounds modified by colonic microbiota change their activity. Absorbed aglycones are broken down into aromatic acids (hydroxyphenylacetic, phenylpropionic, phenylbutyric and other acids), and they enter the bloodstream. In the liver, aglycones undergo methylation, sulfation and/or glucuronidation (Scalbert et al., 2002; D'Archivio et al., 2007; Brenes et al., 
2016). Selected flavonoid metabolites are excreted to bile and reabsorbed from the intestine via enterohepatic circulation (Majewska and Czeczot, 2009).

The content of polyphenols in bodily tissues is not directly related to their dietary levels (D’Archivio et al., 2007; Fotina et al., 2013; Surai, 2014). In pigs administered a single dose of quercetin at $25 \mathrm{mg} / \mathrm{kg} \mathrm{BW}$, the concentrations of this polyphenol were higher in the liver $(6.20 \mathrm{nmol} / \mathrm{g})$, kidneys $(2.84 \mathrm{nmol} / \mathrm{g})$ and jejunum $(2.36 \mathrm{nmol} / \mathrm{g})$ than in plasma $(1.48 \mu \mathrm{mol} / \mathrm{l})$ or muscles $(0.11 \mathrm{nmol} / \mathrm{g})$. In pigs whose diets were supplemented with quercetin $(50 \mathrm{mg} / \mathrm{kg} \mathrm{BW})$ for 4 weeks, quercetin levels were higher in the kidneys $(6.31 \mathrm{nmol} / \mathrm{g})$ and colon $(13.92 \mathrm{nmol} / \mathrm{g})$ than in the liver $(2.83 \mathrm{nmol} / \mathrm{g})$ or plasma $(0.67 \mu \mathrm{mol} / \mathrm{l})$. Trace amounts of the examined polyphenol $(0.09 \mathrm{nmol} / \mathrm{g})$ were observed in muscles (Bieger et al., 2008). Similar quercetin concentrations were reported by Wein and Wolffram (2012) in the plasma $(0.69 \mu \mathrm{mol} / \mathrm{l})$ of horses administered a single dose of this flavonoid $(20 \mathrm{mg} / \mathrm{kg} \mathrm{BW})$. When pig diets were supplemented with higher doses of quercetin $(500 \mathrm{mg} / \mathrm{kg} \mathrm{BW})$ for 3 days, quercetin levels remained unchanged in bodily tissues $(3.78 \mathrm{nmol} / \mathrm{g}$ in the liver, $1.84 \mathrm{nmol} / \mathrm{g}$ in the kidneys), but increased in plasma $(1.1 \mu \mathrm{mol} / \mathrm{l})$ (Boer et al., 2005). Small amounts of isoflavones such as daidzein and genistein are also accumulated in the liver. In sows whose diets were supplemented with genistein at $2.3 \mathrm{~g} / \mathrm{kg}$ of feed (pure genistein + soybean-based commercial diet), genistein concentrations in the liver were determined at $2.04 \mathrm{nmol} / \mathrm{g}$, and daidzein concentrations - at $1.18 \mathrm{nmol} / \mathrm{g}$ (Gilani et al., 2011). Those results indicate that higher polyphenol doses and longer periods of administration do not contribute to the accumulation of the evaluated compounds in bodily tissues. Elevated polyphenol concentrations were noted only in organs that participate in the metabolism of polyphenolic compounds.

Polyphenols are characterized by low bioavailability and urinary excretion ranges from $0.3 \%$ for anthocyanins to $43 \%$ for isoflavones such as daidzein found in soybeans (Han et al., 2007; Landete, 2013). Their availability is determined by the type of compound, its chemical and physical properties, and the type and presence of functional groups (D’Archivo et al., 2007; Landete, 2013).

\section{Antioxidant effects of polyphenols}

During oxidative stress, free radicals are produced in excessive quantities that cannot be effectively neutralized by the body (Durand et al., 2013; Zhong and Zhou, 2013). Reactive oxygen species (ROS) damage DNA and entire chromosomes, modify amino acids, contribute to protein fragmentation, intensified lipid peroxidation in cell membranes, cell apoptosis and necrosis which increase the risk of inflammations and cancer (Lykkesfeldt and Svendsen, 2007; Leopoldini et al., 2011; Landete, 2013). In homeostasis, ROS and reactive nitrogen species are deactivated by the triad of enzymatic antioxidants (superoxide dismutase, catalase and glutathione peroxidase) and low-molecular-weight antioxidants (tocopherols, ascorbic acid) (Paszkiewicz et al., 2012; Durand et al., 2013; Landete, 2013). Exogenous antioxidants form the first line of defense against excessive ROS generation. They include polyphenols which protect cell components against oxidative damage caused by free radicals, thus reducing the risk of neurodegenerative diseases associated with oxidative stress (D’Archivio et al., 2007; Zhong and Zhou, 2013). Among all polyphenolic com- 
pounds, flavonoids are most effective in removing the generated free radicals, which can be attributed to 3 factors: the presence of an o-diphenolic group, a 2-3 double bond coupled with a 4-oxo function, and a hydroxyl group located at positions 3 and 5 (Majewska and Czeczot, 2009; Landete, 2013). In addition, polyphenols restrict the generation of ROS in the cells by inhibiting the activity of pro-oxidant enzymes (membrane-associated NAD(P)H oxidase, xanthine oxidase, and protein kinase $\mathrm{C}$ ) which participate in the intracellular electron transport chain (Procházková et al, 2011; Fraga et al., 2010). Moreover, phenolic compounds may indirectly prevent chelation of transition metal ions, e.g. iron and copper, thus restricting the formation of reactive hydroxyl radicals (HO•) (Halliwell, 2008; Majewska and Czeczot, 2009). Mitigation of the effects of oxidative stress caused by nitric oxide NO• or hypochlorous acid, and the possibility for the direct removal thereof, are another manifestation of the activity of polyphenols in the fight against the oxidative stress (Leopoldini et al., 2011; Surai, 2014). The most intense activity in restricting the generation of $\mathrm{NO} \bullet$ is exhibited by apigenin, diosmetin, and luteolin, all belonging to the group of flavones (Procházková et al., 2011). An increase in the total antioxidant capacity of plasma, resulting from the consumption of products rich in polyphenols, is associated with an increase in the plasma levels of uric acid (Lotito and Frei, 2006). The stabilization of low-molecular-weight antioxidants, such as ascorbate or vitamin E, by polyphenols (mostly quercetin and rutin) prevents their oxidation (Majewska and Czeczot, 2009; Paszkiewicz et al., 2012).

The complete replacement of vitamin $\mathrm{E}$ with polyphenols in livestock diets is not justified (Surai, 2014). Tocopherols are not only effective antioxidants, but they also control various biochemical and physiological processes in living organisms, including growth, development, reproduction and resistance (Fotina et al., 2013; Surai, 2014).

\section{Pro-oxidant effects of polyphenols}

In environments characterized by increased partial pressure and concentration of oxygen, polyphenols can exert pro-oxidant effects on other cells. In flavonoids, this action is facilitated by their specific chemical structure, the presence of pyrogallol or catechol structures (three $\mathrm{OH}$ groups or one $\mathrm{OH}$ group at the 3 position on the B-ring), the presence of oxygen and copper ions $\left(\mathrm{Cu}^{2+}\right)$ (Majewska and Czeczot, 2009; Procházková et al., 2011).

The same flavonoids can exert both negative and positive effects, subject to the source and concentrations of free radicals and polyphenol concentrations in the administered dose (Gryszczyńska and Iskra, 2008; Procházková et al., 2011). The pro-oxidant properties of dietary polyphenols can be exacerbated due to glutathione (GSH) deficiency in cells, lack of chemical stability and activation of cellular copper ions $\left(\mathrm{Cu}^{1+}\right)(\mathrm{Hu}, 2011)$ which are produced during auto-oxidation together with semiquinone radicals (oxidized flavonoid) (Majewska and Czeczot, 2009). The cytotoxic semiquinone radical is reduced by NADH, and it participates in the generation of ROS in redox reactions (Procházková et al., 2011). Copper ions increase the concentrations of superoxide radicals which contribute to the generation of hydrogen peroxide and highly reactive hydroxyl radicals (Majewska and Czeczot, 2009). 
Flavonoids containing a catechol group (catechol, quercetin, luteolin) can affect the oxidation of ascorbic acid and decrease its concentration (Gryszczyńska and Iskra, 2008; Procházková et al., 2011). Despite the above, the pro-oxidant action of polyphenols can also deliver positive effects by inducing mild oxidative stress, generating antioxidants and xenobiotic-metabolizing enzymes, and contributing to overall cytoprotective effects (Halliwell, 2008; Procházková et al., 2011). Polyphenols are highly susceptible to auto-oxidation in vitro (Halliwell, 2007), and further research is needed to investigate their pro-oxidant effects on animal cells.

\section{Health-promoting properties of polyphenols}

Polyphenols are characterized by high antioxidant activity due to their complex chemical structure and the presence of various groups in a molecule. They also exert non-specific effects on cell metabolism and deliver a host of health benefits for humans and animals (Petti and Scully, 2009; Kamboh et al., 2015).

Flavonoids positively affect the circulatory system by inhibiting the progression of cardiovascular diseases. The above can be attributed mainly to their antioxidant properties because oxidative stress contributes to vascular damage and oxidation of plasma lipids. Flavonoids inhibit peroxidation of low-density lipoproteins, which are associated with "bad" cholesterol, and minimize oxidation of membrane lipids. Anthocyanins scavenge free radicals and prevent plaque buildup in the arteries. Polyphenols present in red wine and grapes (catechins and resveratrol) have vasodilatory effects, and they prevent arrhythmia (Han et al., 2007; Pandey and Rizvi, 2009; Chiva-Blanch and Visoli, 2012). In recent research, much attention has also been given to the modification of animal products with biologically active compounds such as polyphenols. Modifications of the fatty acid profile, mostly by decreasing the concentrations of saturated fatty acids (SFAs) and increasing the levels of polyunsaturated fatty acids (PUFAs) in muscle tissue, can indirectly contribute to consumer health by improving the quality of food products and increasing their oxidative stability (Brenes et al., 2008; Kamboh and Zhu, 2013 a).

Polyphenols also play therapeutic and protective roles in cancer. By minimizing the negative effects of oxidative stress, i.e. lipid, protein and nucleic acid damage caused by oxygen radicals, polyphenols prevent carcinogenic changes (Scalbert et al., 2005; Paszkiewicz et al., 2012). Anthocyanins can block cellular divisions in different phases of the cell cycle (G1/S or G2/M) by inhibiting kinase enzymes, such as tyrosine kinase, which are responsible for signal transmission between cells (Majewska and Czeczot, 2009). The above disrupts cell growth and cell division, and it inhibits the proliferation of cancer cells (Zalega and Szostak-Węgierek, 2013). Polyphenols also play a role in apoptosis - programmed cell death. Flavonoids such as daidzein and quercetin exert anticarcinogenic effects on leukemia cell lines, hormone-dependent cell lines (breast and prostate cancer), gastric and colorectal cancer cell lines (Zalega and Szostak-Węgierek, 2013; Lima et al., 2014).

Isoflavone group flavonoids such as genistein and daidzein are structurally similar to estradiol (hydroxyl groups at the $\mathrm{C} 4$ and $\mathrm{C} 7$ positions), and they can bind to estrogen receptors alpha (mammary glands and ovaries) and beta (brain, kidneys and lungs) (D’Archivio et al., 2007; Majewska and Czeczot, 2009). Those flavonoids, 
known as phytoestrogens, alleviate the symptoms of menopause and prevent osteoporosis in women (Landete, 2013; Kamboh et al., 2015).

\section{Gut health and immunomodulatory effects}

Polyphenols are characterized by low bioavailability, and unabsorbed compounds exert a significant influence on gut health (Etxeberria et al., 2013; Brenes et al., 2016). Phenolic compounds have bactericidal (Gordon and Wareham, 2010) and bacteriostatic properties (Etxeberria et al., 2013), they minimize the adhesion of pathogenic bacteria (E. coli, Clostridium), inhibit the progression of infections in the digestive tract, improve nutrient utilization and animal performance (Viveros et al., 2011; Dueñas et al., 2015; Brenes et al., 2016). The pro-oxidant properties of polyphenols are also responsible for their antimicrobial activity. Metal ions and oxygen promote the formation of phenoxyl radicals which have cytotoxic effects and damage bacterial DNA. Anthocyanins present in cherries, raspberries and berries demonstrate bacteriostatic and bactericidal effects (Bacillus, Klebsiella, Helicobacter). Due to the presence of hydroxyl groups, polyphenols (quercetin) have the ability to incorporate into lipid membranes and increase their permeability, which makes pathogens more sensitive to antibacterial compounds (Chiva-Blanch and Visoli, 2012; Paszkiewicz et al., 2012).

By enhancing the proliferation of beneficial bacteria (Bacillus spp., Lactobacillus spp.) and stabilizing gut microflora, polyphenols indirectly enhance the host's immune system and overall health (Hashemi and Davoodi, 2011; Paszkiewicz et al., 2012). They can exert a positive influence on gut morphology and improve nutrient absorption in monogastric animals (Kamboh et al., 2015).

In a study by Hong et al. (2012), essential oils (total polyphenolic compounds $13.3 \mathrm{mg} / \mathrm{g}$ diet) significantly increased the height of intestinal villi in the duodenum of broiler chickens without inducing any changes in the composition of ileal microflora. In an experiment conducted by Kamboh and Zhu (2014), genistein, hesperidin and flavonoids extracted from Ginkgo biloba leaves (Zhang et al., 2013) significantly increased the surface area of the small intestine available for nutrient absorption and modified its structure (length and width of villi, crypt depth) in broilers exposed to lipopolysaccharide stress (LPS-endotoxin present on the outer walls of Gram-negative bacteria). In the work of Zhang et al. (2014), dietary polyphenols had no significant influence on piglet performance or fecal E. coli and Clostridia counts on days 11 and 21 of the experiment. Kirkpinar et al. (2011) reported a decrease in Clostridium populations in the ileum of chickens fed oregano oil, garlic oil and both substances in comparison with animals from the remaining groups. Dietary supplementation with cranberry extract ( $80 \mathrm{mg} / \mathrm{kg}$ of feed), a rich source of phenolic acids, anthocyanins, flavonols and flavan-3-ols, significantly decreased the size of Enterococcus spp. populations in broilers on day 28 of the experiment (Leusink et al., 2010).

Pigs whose diets were supplemented with polyphenol-rich grape seeds, grape marc meal extract or spent hops were characterized by higher $\mathrm{pH}$ of intestinal digesta and significantly lower counts of Streptococcus spp. and Clostridium cluster XIVa in fecal microbiota. Their gain/feed ratio was higher in comparison with control group piglets (Fiesel et al., 2014). Heat-stressed chickens fed grape seed extract in the 
amount of 300 and $450 \mathrm{mg} / \mathrm{kg}$ of feed were characterized by lower ileal counts of Escherichia coli and coliform bacteria on day 42 in comparison with control group birds $(\mathrm{P} \geq 0.05)$. Chickens whose diets were enriched with polyphenols or vitamin $\mathrm{C}$ had longer intestinal villi than control group birds $(\mathrm{P} \geq 0.05)$ (Hajati et al., 2015). Similar results were reported by Akbarian et al. (2013) in whose study, E. coli counts decreased significantly in the ileum and cecum of chickens fed $400 \mathrm{mg} / \mathrm{kg}$ of lemon peel extract or Curcuma xanthorrhiza essential oil during chronic exposure to high temperatures $\left(34^{\circ} \mathrm{C} / 5 \mathrm{~h} / \mathrm{d}\right)$. Viveros et al. (2011) observed an increase in Lactobacillus counts in the ileum of control group birds and birds fed grape seed extract in comparison with birds receiving an antibiotic or grape pomace concentrate.

Acute inflammation and excessive or inadequate immune responses can cause chronic inflammations and various diseases. Polyphenols exert immunomodulatory effects by controlling enzymes and cytokines and by partial regulation of the activity of transcription factors such as the nuclear factor-kappaB (NF- $\kappa \mathrm{B})$ (Chiva-Blanch and Visoli, 2012; Paszkiewicz et al., 2012). Flavonoids limit inflammatory processes by inhibiting the activity of signaling compounds that initiate the inflammatory response - 5-lipoxygenase (5-LOX) and cyclooxygenase (COX) enzymes - which participate in the synthesis of prostaglandins and leukotrienes from arachidonic acid (D’Archivio et al., 2007; Majewska and Czeczot, 2009). Polyphenols can minimize the harmful effects of free radicals and reactive oxygen species produced during the immune response, thus enhancing immune system function (Kamboh et al., 2015).

Genistein, hesperidin (Kamboh and Zhu, 2014) and flavonoids derived from fermented Ginkgo biloba leaves (Zhang et al., 2013) improved immune parameters in broilers exposed to LPS-induced stress by lowering the expression of interleukins IL-4, IL-13, IL-18 and IFN- $\gamma$ in comparison with birds from other groups, and led to positive changes in phagocytic activity in the second experiment. Zhu et al. (2015) investigated the effect of soy isoflavones on weaned piglets challenged with LPS. Soy isoflavones, a rich source of genistein, daidzein, biochanin A and glycitein with immunomodulatory properties, administered to piglets in the amount of $40 \mathrm{mg} / \mathrm{kg}$ of feed significantly lowered the incidence of diarrhea, and decreased the concentrations of endotoxin (0.60 vs. $0.98 \mathrm{EU} / \mathrm{ml})$ and MDA (2.69 vs. $3.18 \mathrm{nmol} / \mathrm{ml})$ in the blood plasma, compared with piglets challenged with LPS.

Grape seed procyanidins (GSPs) are polyphenols with anti-inflammatory and immunomodulatory properties. When administered to weaned piglets in the amount of 100 or $150 \mathrm{mg} / \mathrm{kg}$ of feed, GSPs significantly increased the concentrations of immunoglobulins IgG, IgM, complement 4 (C4) and interleukin-2 (IL-2), they improved the animals' antioxidant status (T-AOC), enhanced GPx and SOD activity, and lowered serum MDA levels in comparison with animals from the remaining groups. The incidence of diarrhea was lowered significantly by around 3-4\% in piglets receiving GSPs relative to control group animals (Hao et al., 2015). Commercial polyphenol preparations (containing hydrolysable tannin or grape seed extract) were effective in decreasing the incidence of diarrhea in piglets infected with enterotoxigenic Escherichia coli (Verhelst et al., 2014). Diets rich in polyphenols from grape seeds and grape pomace significantly lowered the activity of inflammatory mediators $\mathrm{NF}-\kappa \mathrm{B}$ and Nrf2, thus reducing the risk of intestinal diseases (Gessner et al., 2013). 
In piglets exposed to oxidative stress induced by intraperitoneal administration of diquat, dietary supplementation with tea polyphenols (500 mg TP/kg diet) enhanced the cell-mediated immune response (by decreasing the IFN-g/IL-4 ratio) and decreased the secretion of IFN- $\gamma$ proinflammatory cytokines, which testifies to the immunomodulatory potential of tea polyphenols (Deng et al., 2010).

The use of polyphenols in monogastric nutrition can improve gut health. Polyphenols have bacteriostatic properties, and they reduce the incidence of diarrhea, in particular in piglets, while stimulating the growth of beneficial microflora. In animals exposed to oxidative stress, polyphenols can enhance immunity by activating immunoglobulins and inhibiting the secretion of proinflammatory cytokines.

\section{Antioxidant effects in monogastric animals}

The antioxidant properties of polyphenolic compounds may be directly used in animal nutrition. They can be applied as preservatives in compound feedingstuffs to protect animals against the negative consequences of oxidation of feed components, in particular feeds with a high content of unsaturated fat. Phenolic compounds can also be used to prevent oxidative stress in animals, and consequently, to stabilize the antioxidant potential of products of animal origin, such as meat or eggs (Wallace et al., 2010).

The parallel supplementation of compound feedingstuffs for monogastrics with the addition of polyphenols and vitamin E shows greater effectiveness in the prevention of adverse effects of the oxidative stress. This results from the antioxidant properties of low molecular weight antioxidants (e.g. ascorbate in cytosol, $\alpha$-tocopherol in biological membranes) and their synergistic properties (vitamin $\mathrm{C}$ and polyphenols regenerate $\alpha$-tocopherol) (Luehring et al., 2011; Voljč et al., 2013). In a study by Lipiński et al. (2015 a), sows whose diets were supplemented with vitamin E and natural polyphenols (onion and grape seed extracts, 50:50) were characterized by similar fertility, mating success and litter size in comparison with animals receiving vitamin E only. Pigs fed both supplements had similar or even higher vitamin E levels and improved antioxidant status than animals receiving only 100-150 mg vitamin E/kg feed (pregnancy/lactation). In a study of broiler chickens, birds fed polyphenol-enriched diets were characterized by similar (SOD) or higher (TAS, GPx) antioxidant status than animals whose diets were supplemented with vitamin $\mathrm{E}$ (Lipiński et al., 2015 b). Sobotka et al. (2012) also noted that the addition of oat byproducts which are a source of phenolic compounds (hydroxybenzoic acid, hydroxycinnamic acid, and their derivatives) to the pigs' diet with an addition of $3 \%$ linseed oil, resulted in an improvement of the antioxidant status of plasma, and reduced the susceptibility of lipids to peroxidation (a lower content of TBARS following the entire storage period). However, the supplementation of a compound feedingstuff with vitamin $\mathrm{E}$ was more effective since it increased the concentration of $\alpha$-tocopherol in the muscles and plasma.

Bioflavonoids such as hesperidin and genistein can exert synergistic effects and provide antioxidant protection. Diets supplemented with hesperidin and genistein in the amount of $5 \mathrm{mg} / \mathrm{kg}$ of feed significantly improved total antioxidant capacity and lowered plasma MDA levels in broilers relative to birds from the remaining groups. 
SOD activity in the blood increased with an increase in polyphenol concentrations in feed (Kamboh and Zhu, 2013 a). In an experiment conducted by Ting et al. (2011), the addition of hesperetin and naringenin (extracted from orange peel) in the amount of $2 \mathrm{~g} / \mathrm{kg}$ of feed led to a substantial improvement in the serum antioxidant status of laying hens by increasing SOD and CAT activity. In a study by Zhang et al. (2014), the addition of plant polyphenols (apples, grape seeds, green tea leaves and olive leaves) to diets of piglets weaned at 21 days of age significantly decreased MDA concentrations in plasma relative to the control group (3.64 vs. $1.93 \mathrm{nmol} / \mathrm{mL})$. Despite the above, no differences in total antioxidant capacity (T-AOC) or the concentrations of catalase (CAT), superoxide dismutase (SOD) and glutathione peroxidase (GSH-Px) were noted between groups.

Grapes, grape seeds and grape pomace are rich sources of flavonoids, including monomeric phenolic compounds such as catechins, epicatechins and procyanidins (Brenes et al., 2008; Surai, 2014). The use of those antioxidants in animal feeds has been investigated by various authors. In broiler chickens, the dietary supplementation with grape pomace in the amount of $60 \mathrm{~g} / \mathrm{kg}$ of diets improved antioxidant activity in breast muscles, excreta $(74.7 \mu \mathrm{mol} / \mathrm{g}$ in the control group $v s .107 .2 \mu \mathrm{mol} / \mathrm{g}$ of the Trolox equivalent/g in the experimental group) and ileal contents without compromising performance, the size of digestive tract organs or protein digestibility (Brenes et al., 2008). Similar results were reported in broilers fed diets with the addition of grape seed extract (3.6 g/kg of feed) (Brenes et al., 2010). Gessner et al. (2013) analyzed the effect of porcine diets supplemented with 1\% polyphenols (grape seeds and grape pomace) on the immune and antioxidant status of 24 six-week-old pigs. After four weeks of feeding the experimental diets, no significant differences in the concentrations of thiobarbituric acid reactive substances (TBARS), $\alpha$-tocopherol or Trolox equivalent antioxidant capacity (TEAC) in liver and plasma were observed between groups.

Tamarind seed extract (Tamarindus indica L.), a rich source of tannins, anthocyanidins and oligomeric anthocyanidins, administered to chickens exposed to heat stress $\left(38^{\circ} \mathrm{C}\right.$ for 6 hours daily) only at the beginning of the experiment at $400 \mathrm{mg} / \mathrm{kg}$ (weeks 1-2) and $500 \mathrm{mg} / \mathrm{kg}$ of feed (week 2), significantly reduced blood MDA levels (Aengwanich and Suttajit, 2010). Polyphenols administered in pure form or with plant-based diets have antioxidant properties which are enhanced in the presence of vitamin $\mathrm{E}$ or other polyphenols by delivering synergistic effects.

\section{Growth performance}

The supplementation of animal diets with polyphenols did not exert a clear influence on the growth performance of animals, which improved, deteriorated or remained unchanged, depending on the compound administered with feed. Inhibited secretion of digestive enzymes, higher protein excretion and lower digestibility of protein and amino acids may exert adverse metabolic effects manifested by a decrease in body weight and feed efficiency (Rohn et al., 2006; Brenes et al., 2010; Chamorro et al., 2013).

Fiesel et al. (2014) reported a significant decrease in the digestibility of total protein and crude fiber in weaned piglets whose diets were supplemented with spent 
hops, a source of natural polyphenols. Dietary supplementation did not compromise performance, and the gain/feed ratio was improved in the experimental group relative to control group animals (638 vs. $579 \mathrm{~g} / \mathrm{kg})$.

The addition of Moringa oleifera, a source of quercetin and kaempferol, to chicken diets contributed to a significant increase in body weights relative to control group birds $(928 ; 932.5 ; 954.6$ vs. 887.6; $918.7 \mathrm{~g})$ at 21 days of age, and improved the feed conversion ratio $(1.47 ; 1.44 ; 1.45$ vs. 1.53$)$ relative to positive controls throughout the experiment (Nkukwana et al., 2014). The supplementation of chicken diets with $0.2 \%$ plant extracts from Chelidonium majus, Lonicera japonica and Saposhnikovia divaricata (sources of flavonoids, tannins, phenolic compounds, saponins, terpenoids and essential oils) led to a significant increase in final body weights (1949; $1930 ; 1930$ vs. $1845 \mathrm{~g}$ ) and increased daily weight gains by approximately $3 \mathrm{~g}$ in comparison with control group birds (Park et al., 2014).

In a study by El-Iraqi et al. (2013), heat-stressed chickens $\left(32-40^{\circ} \mathrm{C}\right)$ were fed diets with the addition of dry peppermint and Ginkgo biloba (sources of flavonoids) which significantly increased final body weights and reduced the feed conversion ratio relative to birds whose diets were supplemented with individual herbs or vita$\min$ C.

Viveros et al. (2011) observed a significant decrease in the body weights of 21 -day-old chickens whose diets were supplemented with grape seed extract $(7.2 \mathrm{~g} / \mathrm{kg}$ of feed) in comparison with birds from the remaining groups (486 g vs. 553; 557; $542 \mathrm{~g}$ ). A significant decrease in the feed conversion ratio was also noted in chickens fed grape pomace concentrate $(60 \mathrm{~g} / \mathrm{kg}$ of feed $)$ or the antibiotic avoparcin $(50 \mathrm{mg} / \mathrm{kg}$ of diet) relative to the remaining birds $(1.43 ; 1.43 v s .1 .51)$. The feed conversion ratio of pigs whose diets were supplemented with polyphenols (from grape seeds and grape pomace) increased relative to the control group (652 vs. $624 \mathrm{~g} / \mathrm{kg} ; \mathrm{P}<0.05)$ (Gessner et al., 2013). In an experiment by Lipiński et al. (2015 b), feed supplementation with polyphenols (grape seeds and onions) did not influence the growth performance, carcass dressing percentage, breast muscle yield or meat composition in broilers.

Broilers aged 22-36 days, fed gallic acid and linoleic acid (1\% of the diet), were characterized by significantly improved performance parameters (feed efficiency of 1.95 vs. 2.06, weight gains) in comparison with control group birds or broilers whose diets contained a smaller dose of the supplement (0.5\%) (Jung et al., 2010).

In a study by Flis et al. (2007), phenolic compounds present in naked oat grain fed to growing-finishing pigs (45\% of the diet) did not influence the growth performance of animals or carcass leanness. Dietary supplementation with cranberry extract, a rich source of phenolic compounds, did not affect body weight or feed efficiency in poultry (Leusink et al., 2010).

Simitzis et al. (2011) demonstrated that dietary supplementation with hesperidin and tocopherol acetate had no significant effect on the growth performance or carcass weight of broilers. In a study by Goliomytis et al. (2015), hesperidin and naringin added to the diets of Ross 308 chickens in the amount of 0.75 or $1.5 \mathrm{~g} / \mathrm{kg}$ of feed did not influence bird performance. In contrast, Kamboh and Zhu (2013 b) reported an increase in the final body weights of broiler chickens whose feed was supple- 
mented with $20 \mathrm{mg} / \mathrm{kg}$ of hesperidin in comparison with birds from the remaining groups. The lowest feed conversion ratio was noted in broilers administered hesperidin only $(20 \mathrm{mg} / \mathrm{kg}$ of feed $)$ or a mixture of hesperidin and genistein $(10 \mathrm{mg} / \mathrm{kg}$ of feed).

The addition of grape byproducts did not improve performance parameters, whereas flavonoid-rich herbs delivered positive results, in particular in heat-stressed animals.

\section{Product quality}

Foods rich in polyunsaturated fatty acids (PUFAs) deliver health benefits, but PUFAs also promote lipid peroxidation in muscle tissues and deteriorate the quality of food products by inducing adverse changes in the flavor, aroma and color of meat. Those processes lead to the formation of harmful products of free radical reactions, such as malondialdehyde (MDA). Oxidative damage in tissues should be prevented at an early stage by controlling animal diets (Gobert et al., 2010; Jung et al., 2010; Brenes et al., 2016).

Jung et al. (2010) reported that gallic acid (a polyphenol found in grapes, wine and tea) and linoleic acid (1\% of diets) improved the nutritional value (higher concentrations of arachidonic acid and docosahexaenoic acid) and water-holding capacity of breast broiler meat. Flis et al. (2010) noted that in a diet enriched with $\alpha$-linolenic acid in parallel with vitamin E deficiency, the phenolic compounds present in cereal and buckwheat grains are not sufficient to maintain the oxidative stability of pork. The authors also determined the total phenolic content (TPC) and the in vitro antioxidant capacity (TAC) of the tested feed materials which were ranked in the following descending order: buckwheat hulls and bran $>>$ barley $>>$ naked oat $\approx$ triticale. In another experiment, the authors demonstrated that the addition of $45 \%$ of naked oat grains (source of phenolic compounds) to the fatteners' diet with an increased content of PUFA had a positive effect on the quality of pork, since its oxidative stability, as measured based on the generation of TBARS products, increased (Flis et al., 2007).

Rosemary is a rich source of polyphenols (carnosol, rosmanol, 7-methyl-epirosmanol, isorosmanol, carnosic acid, rosmarinic acid, caffeic acid), and it can alleviate the negative consequences of oxidative stress. The addition of dry rosemary leaves and rosemary essential oil improved the sensory attributes of meat and significantly decreased MDA concentrations in the breast muscles of broiler chickens in comparison with birds whose diets were supplemented only with $\alpha$-tocopherol (Yesilbag et al., 2011).

Quercetin, a flavonol found in fruit and vegetables, is a powerful antioxidant. Feed supplementation with $300 \mathrm{mg}$ of quercetin and $300 \mathrm{mg}$ of $\alpha$-tocopherol $/ \mathrm{kg}$ feed decreased the concentrations of thiobarbituric acid reactive substances and saturated fatty acids in the breast muscles of broilers which were characterized by the highest $(\mathrm{P} \leq 0.05)$ concentrations of $\alpha$-tocopherol and quercetin in comparison with breast muscle samples from the remaining groups (Sohaib et al., 2015).

In an experiment by Voljč et al. (2013), the parallel incorporation of $\alpha$-tocopherol and sweet chestnut wood extract (rich in tannins) to a feed ration with an increased 
content of PUFA improved the immunity from lipid oxidation, and increased the concentration of total tocopherols in the meat of broiler chickens. In addition, it was found that the supplementation of the ration with vitamin $\mathrm{E}$ (both at an amount of $85 \mathrm{IU} / \mathrm{kg}$ and $200 \mathrm{IU} / \mathrm{kg}$ of diets), or only the addition of $3 \mathrm{~g} / \mathrm{kg}$ of a product containing polyphenols, are not sufficient to prevent the adverse effects of lipid peroxidation. Similarly, polyphenols extracted from green tea, a source of catechins (epigallocatechin-3-gallate, epicatechin-3-gallate and epigallocatechin), which were added to the diets of growing pigs over a period of 5 weeks in the amount of 10 and $100 \mathrm{mg} / \mathrm{kg}$ of BW had no effect on vitamin E concentrations in plasma, liver and muscles, the antioxidant status or the quality of meat (Augustin et al., 2008). On the other hand, in a study by Luehring et al. (2011), the supplementation of a complete diet for pigs with a reduced vitamin E content, with quercetin at $10 \mathrm{mg} / \mathrm{kg}$ of BW resulted in an increase in the amount of $\alpha$-tocopherol, and exhibited antioxidant properties for a dose with an increased content of fish oil. Similar results were reported by Botsoglou et al. (2012) in whose study, the administration of $\alpha$-tocopherol improved the antioxidant status of eggs enriched with $n-3$ fatty acids. Diets for laying hens were supplemented with $4 \%$ linseed oil, $200 \mathrm{mg} / \mathrm{kg}$ of $\alpha$-tocopherol, 5 or $10 \mathrm{~g}$ olive leaves $/ \mathrm{kg}$ feed. Throughout the entire storage period, vitamin E was more effective in reducing MDA concentrations in eggs than the addition of $10 \mathrm{~g} / \mathrm{kg}$ olive leaves which are abundant in polyphenols. In a study by Ting et al. (2011), feed supplementation with naringenin and hesperetin in the amount of $2 \mathrm{~g} / \mathrm{kg}$ of feed improved egg quality by significantly lowering total cholesterol levels and increasing yolk weight (naringenin) in comparison with eggs from the remaining groups.

Hesperidin, a bioflavonoid found in citrus fruit, is a powerful antioxidant. When added to broiler diets in the amount of $3 \mathrm{~g} / \mathrm{kg}$ of feed, hesperidin significantly influenced the $\mathrm{pH}$ and color, and lowered MDA concentrations in breast muscles after 3 , 6 and 9 days of storage relative to the control group. Tocopherol acetate administered to chickens at $2 \mathrm{~g} / \mathrm{kg}$ of feed was characterized by higher antioxidant potential than both doses of hesperidin (11.33 vs. 44.94; 52.27 ng/g MDA; $\mathrm{P} \leq 0.05$ ) (Simitzis et al., 2011). Similar results were reported by Goliomytis et al. (2015) in a study of broilers where vitamin $\mathrm{E}$ was the most potent antioxidant $(\mathrm{P} \leq 0.05)$, but hesperidin and naringin administered at $1.5 \mathrm{~g} / \mathrm{kg}$ of feed also reduced MDA concentrations in breast muscles after 6 days of storage relative to the tissues of control group birds (6.64 vs. 8.06; 9.03 vs. $12.16 \mathrm{ng}$ MDA/g meat). Dietary supplementation with polyphenols did not affect the color, cooking loss or $\mathrm{pH}_{24}$ of breast muscles. In another experiment, the addition of hesperidin and genistein in the amount of $20 \mathrm{mg} / \mathrm{kg}$ of feed significantly influenced $(\mathrm{P} \leq 0.05)$ color lightness $\left(\mathrm{L}^{*}\right)$, increased $\mathrm{pH}_{48}(5.97$ vs. 5.79) and improved the water holding capacity $(55.00 \%$ vs. $49.42 \%)$ of broiler meat relative to control. In breast muscles stored for 15 days, MDA concentrations were lowest in the group whose diets were supplemented with the highest polyphenol dose (2.16 vs. $5.72 \mathrm{nmol} \mathrm{MDA} / \mathrm{mg}$ protein). Dietary supplementation did not influence the sensory attributes of broiler meat (Kamboh and Zhu, 2013 b). In another experiment, the addition of hesperidin and genistein to broiler diets improved the fatty acid profile (PUFAs, $n-6: n-3$ PUFA ratio) of breast muscles $(\mathrm{P} \leq 0.05)$ (Kamboh and Zhu, 2013 a). 
Polyphenols improve the quality of animal products, minimize the adverse consequences of lipid peroxidation by decreasing MDA concentrations and increasing tocopherol levels in tissues. Vitamin E is a more potent antioxidant than polyphenols.

Extensive research has proven that polyphenols, powerful antioxidants which are ubiquitous in plants, constitute a valuable supplement for animal diets. Those biologically active compounds improve the quality of animal products and contribute to animal health and performance. They minimize the adverse effects of lipid peroxidation (by lowering MDA levels), improve the antioxidant status of animals (by increasing the concentrations of vitamin $\mathrm{E}$, vitamin $\mathrm{C}$ and antioxidant enzymes in blood and muscles), inhibit the proliferation of pathogenic bacteria in the gastrointestinal tract, and improve gut health. Despite the above, polyphenols exert an ambiguous effect on nutrient digestibility and growth performance. For this reason, further research is required to investigate the efficacy of polyphenols in animal nutrition.

\section{References}

A e n g w a n i ch W., S u t t a j it M. (2010). Effect of polyphenols extracted from Tamarind (Tamarindus indica L.) seed coat on physiological changes, heterophil/lymphocyte ratio, oxidative stress and body weight of broilers (Gallus domesticus) under chronic heat stress. Anim. Sci. J., 81: 264-270.

Akbarian A., Golian A., Kermanshahi H., Farhoosh R., Raji A.R., De Smet S., $\mathrm{Michi}$ els J. (2013). Growth performance and gut health parameters of finishing broilers supplemented with plant extracts and exposed to daily increased temperature. Span. J. Agric. Res., 11: $109-119$.

Augustin K., B lank R., Boesch-Saadatmandi C., Frank J., Wolffram S., Rimb a c h G. (2008). Dietary green tea polyphenols do not affect vitamin E status, antioxidant capacity and meat quality of growing pigs. J. Anim. Physiol. Anim. Nutr. (Berl)., 92: 705-711.

Bieger J., Cermak R., Blank R., de Boer V.C., Hollman P.C., Kamphues J., Wo $1 \mathrm{ffram} \mathrm{S.} \mathrm{(2008).} \mathrm{Tissue} \mathrm{distribution} \mathrm{of} \mathrm{quercetin} \mathrm{in} \mathrm{pigs} \mathrm{after} \mathrm{long-term} \mathrm{dietary} \mathrm{supplemen-}$ tation. J. Nutr., 138: 1417-1420.

B oer de V.C., Dihal A.A., van der Woude H., Arts I.C., Wolffram S., Alink G.M., Ho $11 \mathrm{~m}$ a n P.C. (2005). Tissue distribution of quercetin in rats and pigs. J. Nutr., 135: 1718-1725.

Botsoglou E., Govaris A., Fletouris D., Iliadis S. (2012). Olive leaves (Olea europea L.) and $\alpha$-tocopheryl acetate as feed antioxidants for improving the oxidative stability of $\alpha$-linolenic acid-enriched eggs. J. Anim. Physiol. Anim. Nutr., 97: 740-753.

Brenes A., Viveros A., Goñi I., Centeno C., S a y g o-Ayerdi S.G., Arija I., S a u ra - Ca lix to F. (2008). Effect of grape pomace concentrate and vitamin E on digestibility of polyphenols and antioxidant activity in chickens. Poultry Sci., 87: 307-316.

Brenes A., Viveros A., Goñ i I., Centen o C., S a u ra-Calix to F., Arija I. (2010). Effect of grape seed extract on growth performance, protein and polyphenol digestibilities, and antioxidant activity in chickens. Span. J. Agric. Res., 8: 326-333.

Brenes A., Viveros A., Ch a m orro S., A rija I. (2016). Use of polyphenol-rich grape by-products in monogastric nutrition. A review. Anim. Feed. Sci. Tech., 211: 1-17.

Chamorro S., Viveros A., Centen o C., Romero C., Arija I., Brenes A. (2013). Effects of dietary grape seed extract on growth performance, amino acid digestibility and plasma lipids and mineral content in broiler chicks. Animal, 7: 555-561.

Chiva-Blanch G., Vis ioli F. (2012). Polyphenols and health: Moving beyond antioxidants. J. Berry Res., 2: 63-71.

D'Archivio M., Filesi C., Di B enedetto R., Gargiulo R., Giovannini C., Mase lla R. (2007). Polyphenols, dietary sources and bioavailability. Ann. Ist. Super. Sanita., 43: 348-361. 
Deng Q., Xu J., Yu B., H e J., Z hang K., D ing X., Chen D. (2010). Effect of dietary tea polyphenols on growth performance and cell-mediated immune response of post-weaning piglets under oxidative stress. Arch. Anim. Nutr., 64: 12-21.

Dueñas M., Muñoz-González I., Cueva C., Jiménez-Girón A., Sánchez-Patán F., S a ntos-B u elg a C., B a r tolomé B. (2015). A survey of modulation of gut microbiota by dietary polyphenols. Bio. Med. Res. Int., ID 850902, 15 pp.

Durand D., Dam on M., G obert M. (2013). Oxidative stress in farm animals: general aspects. Cah. Nutr. Diet., 48: 218-224.

E 1 - Ir a q i K.G., A b d e 1 g a w a d E.M., I b r a h i m H.M., E 1 S a w e A.E. (2013). Effect of Ginkgo biloba, dry peppermint and vitamin $\mathrm{C}$ as anti-stress on broiler welfare during summer heat stress. Glob. Vet., 10: 770-778.

Etxeberria U., Fernández-Quintela A., Milagro F.I., Aguirre L., Martínez J A., P ortillo M.P. (2013). Impact of polyphenols and polyphenol-rich dietary sources on gut microbiota composition. J. Agr. Food. Chem., 61: 9517-9533.

F i es el A., Gessner D.K., Most E., Eder K. (2014). Effects of dietary polyphenol-rich plant products from grape or hop on pro-inflammatory gene expression in the intestine, nutrient digestibility and faecal microbiota of weaned pigs. BMC Vet. Res., 10: 1.

Flis M., S ob otka W., Antoszkiew ic z Z., Li piński K., Z duńczyk Z. (2007). Effect of husked and naked oat used in the diets supplemented with linseed oil on the growth performance of pigs, carcass and meat quality. Arch. Tierz. Dummerstorf, Special Issue, 50: 161-171.

F lis M., S obotka W., Antoszki ew i c z Z., Li piński K., Zduń c zyk Z. (2010). The effect of grain polyphenols and the addition of vitamin $\mathrm{E}$ to diets enriched with $\alpha$-linolenic acid on the antioxidant status of pigs. J. Anim. Feed. Sci., 19: 539-553.

F ot in a A.A., F is in in V.I., S u ra i P.F. (2013). Recent developments in usage of natural antioxidants to improve chicken meat production and quality. Bulg. J. Agric. Sci., 19: 889-896.

Frag a C.G., Ga 11 e a no M., Ver stra e te n S.V., O t e iz a P.I. (2010). Basic biochemical mechanisms behind the health benefits of polyphenols. Mol. Aspects. Med., 31: 435-445.

Gessner D.K., Fiesel A., Most E., Dinges J., Wen G., Ring se is R., Eder K. (2013). Supplementation of a grape seed and grape marc meal extract decreases activities of the oxidative stress-responsive transcription factors NF- $\mathrm{B}$ and Nrf2 in the duodenal mucosa of pigs. Acta Vet. Scand., 55: 18-28.

Gil an i G.S., F a r m e r C., D y c k M., R oberts on P., D a hi y a J., S e pe hr E., F a n L., Ni c o li dak is H., C urran I., C o oke G.M. (2011). Distribution of isoflavones in samples of serum, liver and mammary glands of rats or pigs fed dietary isoflavones. Ann. Nutr. Metab., 58: 171-180.

Gobert M., Gruffat D., Habeanu M., Parafita E., Bauchart D., Durand D. (2010). Plant extracts combined with vitamin E in PUFA-rich diets of cull cows protect processed beef against lipid oxidation. Meat. Sci., 85: 676-683.

Goliomyt is M., Kartsonas N., Charis miadou M.A., Symeon G.K., Simitzis P.E., Deli g e orgis S.G. (2015). The influence of naringin or hesperidin dietary supplementation on broiler meat quality and oxidative stability. PloS one, 10(10): e0141652.

Gordon N.C., Wa r e ha m D.W. (2010). Antimicrobial activity of the green tea polyphenol (-)-epigallocatechin-3-gallate (EGCG) against clinical isolates of Stenotrophomonas maltophilia. Int. J. Antimicrob. Ag., 36: 129-131.

Gry s z c z yń s k a B., I s k r a M. (2008). Interaction between exogenous and endogenous antioxidants in the human body (in Polish). Now. Lek., 77: 50-55.

Hajati H., Hassanabadi A., Nassiri Moghaddam H., Nassiri M.R. (2015). The effect of grape seed extract and vitamin $\mathrm{C}$ feed supplements carcass characteristics, gut morphology and ileal microflora in broiler chickens exposed to chronic heat stress. Iran. J. Appl. Anim. Sci., 5: $155-165$.

Ha 11 iw e 11 B. (2007). Dietary polyphenols: good, bad, or indifferent for your health? Cardiovasc. Res., 73: 341-347.

Ha 11 i w e 11 B. (2008). Are polyphenols antioxidants or pro-oxidants? What do we learn from cell culture and in vivo studies? Arch. Biochem. Biophys., 476: 107-112.

Ha 11 iw e 11 B. (2012). The antioxidant paradox: less paradoxical now? Br. J. Clin. Pharmacol., 75: $637-644$. 
H a n X., S h e n T., L o u H. (2007). Dietary polyphenols and their biological significance. Int. J. Mol. Sci., 8: 950-988.

H a o R., Li Q., Zh a o J., Li H., Wang W., G a o J. (2015). Effects of grape seed procyanidins on growth performance, immune function and antioxidant capacity in weaned piglets. Livest. Sci., 178: $237-242$.

H a s h e mi S.R., D a vo od i H. (2011). Herbal plants and their derivatives as growth and health promoters in animal nutrition. Vet. Res. Commun., 35: 169-180.

H o n g J.C., S t e in e r T., A u f y A., L i e n T.F. (2012). Effects of supplemental essential oil on growth performance, lipid metabolites and immunity, intestinal characteristics, microbiota and carcass traits in broilers. Livest. Sci., 144: 253-262.

$\mathrm{H} \mathrm{u}$ M.L. (2011). Dietary polyphenols as antioxidants and anticancer agents: more questions than answers. Chang Gung Med. J., 34: 449-460.

Jasiński M., Mazurkiewicz E., Rodziewi c z P., Figl lerowicz M. (2009). Flavonoids' structure, properties and particular function for legume plants (in Polish). Biotechnologia, 2: 81-94.

J ung S., C h o e J.H., K i m B., Y u n H., Kruk Z.A., J o C. (2010). The effect of dietary mixture of gallic acid and linoleic acid on antioxidative potential and quality of breast meat from broilers. Meat Sci., 86: 520-526.

K a m b o h A.A., Z hu W.Y. (2013 a). Effect of increasing levels of bioflavonoids in broiler feed on plasma anti-oxidative potential, lipid metabolites, and fatty acid composition of meat. Poultry Sci., 92: 454-461.

K a mboh A.A., Zhu W.Y. (2013 b). Individual and combined effects of genistein and hesperidin supplementation on meat quality in meat-type broiler chickens. J. Sci. Food. Agr., 93: 3362-3367.

$\mathrm{K} \mathrm{a} \mathrm{m} \mathrm{b} \mathrm{o} \mathrm{h} \mathrm{A.A.,} \mathrm{Z} \mathrm{hu} \mathrm{W.Y.} \mathrm{(2014).} \mathrm{Individual} \mathrm{and} \mathrm{combined} \mathrm{effects} \mathrm{of} \mathrm{genistein} \mathrm{and} \mathrm{hesperidin} \mathrm{on}$ immunity and intestinal morphometry in lipopolysaccharide-challenged broiler chickens. Poultry Sci., 93: 2175-2183.

K a mboh A.A., A ra in M.A., Mugh a 1 M.J., Z a m an A., A ra in Z.M., S o o m ro A.H. (2015). Flavonoids: Health promoting phytochemicals for animal production $-\mathrm{A}$ review. J. Anim. Health Prod., 3: 6-13.

K 1 rkpınar F., Ünlü H.B., Özdemir G. (2011). Effects of oregano and garlic essential oils on performance, carcase, organ and blood characteristics and intestinal microflora of broilers. Livest. Sci., 137: 219-225.

L a n d e te J.M. (2013). Dietary intake of natural antioxidants: vitamins and polyphenols. Crit. Rev. Food. Sci. Nutr., 53: 706-721.

L e o pold in i M., Rus s o N., To s c a n o M. (2011). The molecular basis of working mechanism of natural polyphenolic antioxidants. Food. Chem., 125: 288-306.

Le us ink G., Rempel H., Skura B., Berkyto M., White W., Yang Y., Fitzpatrick S. (2010). Growth performance, meat quality, and gut microflora of broiler chickens fed with cranberry extract. Poultry Sci., 89: 1514-1523.

Li ma G.P.P., Vianello F., C or rêa C.R., d a S ilva Campos R.A., B orgu in i M.G. (2014). Polyphenols in fruits and vegetables and its effect on human health. Food Nutr. Sci., 5: 1065-1082.

Lipiński K., Antoszkiewi cz Z., Mazur M., Kaliniewi c z J., Makowski Z. (2015 a). Effect of onion and grape seed extracts on meat quality and antioxidant status in broiler chickens. Proc. 20th European Symposium on Poultry Nutrition, 24-27.08.2015, Prague, Czech Republic, 204.

L i p i ń s k i K., K orn i e w i c z D., A n t o s z ki e w i c z Z., M a z u r M. (2015 b). Effect of onion and grape seed extracts on performance and the vitamin E and antioxidant status in sows. Proc. XLIV Scientific Session: Nutrition of livestock, companion and wild animals, Warsaw, 16-17.06.2015, $36 \mathrm{pp}$.

L ot it o S.B., Fre i B. (2016). Consumption of flavonoid-rich foods and increased plasma antioxidant capacity in humans: cause, consequence, or epiphenomenon? Free. Radic. Biol. Med., 41: $1727-1746$.

Luehring M., B lank R., Wolffram S. (2011). Vitamin E-sparing and vitamin E-independent antioxidative effects of the flavonol quercetin in growing pigs. Anim. Feed. Sci. Technol., 169: 199-207.

Lykkesfeldt J., Svendsen O. (2007). Oxidants and antioxidants in disease: oxidative stress in farm animals. Vet. J., 173: 502-511. 
Majewska M., Czeczot H. (2009). Flavonoids in prevention and therapy of diseases (in Polish). Ter. Lek., 65: 369-377.

Man a ch C., S c a l bert A., M or and C., Ré mé s y C., Ji méne z L. (2004). Polyphenols: food sources and bioavailability. Am. J. Clin. Nutr., 79: 727-747.

Myburgh K.H. (2014). Polyphenol supplementation: benefits for exercise performance or oxidative stress. Sports Med. Suppl., 1: 57-70.

Nkukwana T.T., Muchenje V., Pieterse E., Masika P.J., Mabusela T.P., Hoffman L.C., D zama K. (2014). Effect of Moringa oleifera leaf meal on growth performance, apparent digestibility, digestive organ size and carcass yield in broiler chickens. Livest. Sci., 161: $139-146$.

P a n dey K.B., Rizvi S.I. (2009). Plant polyphenols as dietary antioxidants in human health and disease. Oxid. Med. Cell. Longev., 2: 270-278.

P a r k J.H., K a n g S.N., C h u G.M., J in S.K. (2014). Growth performance, blood cell profiles, and meat quality properties of broilers fed with Saposhnikovia divaricata, Lonicera japonica, and Chelidonium majus extracts. Livest. Sci., 165: 87-94.

Pa s z ki e w i c z M., B u d z y n s k a A., R o z a l s k a B., S a d o w s k a B. (2012). The immunomodulatory role of plant polyphenols (in Polish). Post. Hig. Med. Dosw., 66: 637-646.

P et t i S., S c u 11 y C. (2009). Polyphenols, oral health and disease: A review. J. Dent., 37: 413-23.

Procházková D., B o u š ová I., Wi 1 he $1 \mathrm{~m}$ ová N. (2011). Antioxidant and prooxidant properties of flavonoids. Fitoterapia, 82: 513-523.

R o h n S., P e tzke K.J., R aw e 1 H.M., Kroll J. (2006). Reactions of chlorogenic acid and quercetin with a soy protein isolate - Influence on the in vivo food protein quality in rats. Mol. Nutr. Food. Res., 50: 696-704.

S calbert A., Morand C., Manach C., Rémés y C. (2002). Absorption and metabolism of polyphenols in the gut and impact on health. Biomed. Pharmacother., 56: 276-282.

S calbert A., Manach C., Morand C., Remes y C., Jimenez L. (2005). Dietary polyphenols and the prevention of diseases. CRC Crit. Rev. Food Sci. Nutr., 45: 287-306.

S i m i t z i s P.E., S y m e on G.K., C h a r i s m i a d o u M.A.,A y o u t a n t i A.G., D e 1 i g e org is S.G. (2011). The effects of dietary hesperidin supplementation on broiler performance and chicken meat characteristics. Can. Vet. J., 91: 275-282.

Sobotka W., Flis M., Antoszkiewicz Z., Lipiński K., Zduńczyk Z. (2012). Effect of oat by-product antioxidants and vitamin $\mathrm{E}$ on the oxidative stability of pork from pigs fed diets supplemented with linseed oil. Arch. Amin. Nutr., 66: 27-38.

S o h a i b M., B u t t M.S., Sh a b b i r M.A., Sh ah id M. (2015). Lipid stability, antioxidant potential and fatty acid composition of broilers breast meat as influenced by quercetin in combination with $\alpha$-tocopherol enriched diets. Lipids Health Dis., 14: 1-15.

S u ra i P.F. (2014). Polyphenol compounds in the chicken/animal diet: from the past to the future. J. Anim. Physiol. An. N., 98: 19-31.

Teng Z., Yuan C., Zhang F., Huan M., Cao W., Li K., Yang J., Cao D., Zhou S., M e i Q. (2012). Intestinal absorption and first-pass metabolism of polyphenol compounds in rat and their transport dynamics in Caco-2 cells. PLoS One, 7(1), e29647.

T ing S., Ye h H.S., L i e n T.F. (2011). Effects of supplemental levels of hesperetin and naringenin on egg quality, serum traits and antioxidant activity of laying hens. Anim. Feed. Sci. Tech., 163: 59-66.

Verhelst R., Schroyen M., Buys N., Niew old T. (2014). Dietary polyphenols reduce diarrhea in enterotoxigenic Escherichia coli (ETEC) infected post-weaning piglets. Livest. Sci., 160: $138-140$.

Viveros A., Chamorro S., Pizarro M., Arija I., Centeno C., Brenes A. (2011). Effects of dietary polyphenol-rich grape products on intestinal microflora and gut morphology in broiler chicks. Poultry Sci., 90: 566-578.

Volj č M., L e vart A., Ž g u r S., S a l o b i r J. (2013). The effect of alpha-tocopherol, sweet chestnut wood extract and their combination on oxidative stress in vivo and oxidative stability of meat in broilers. Brit. Poultry. Sci., 54: 144-156.

Wa 11 a c e R.J., O les ze k W., Franz C., Hahn I., B a s e r K.H.C., M a the A., Te i ch mann K. (2010). Dietary plant bioactives for poultry health and productivity. Brit. Poultry Sci., 51: $461-487$. 
We in S., Wo $1 \mathrm{ffr}$ a m S. (2013). Oral bioavailability of quercetin in horses. J. Equine Vet. Sci., 33: $441-445$.

Yesilbag D., Eren M., A ge 1 H., Kovanlika y a A., B alci F. (2011). Effects of dietary rosemary, rosemary volatile oil and vitamin $\mathrm{E}$ on broiler performance, meat quality and serum SOD activity. Brit. Poultry Sci., 52: 472-482.

Z a l e g a J., S z o s t a k - W ę g i e r e k D. (2013). Nutrition in cancer prevention. Part I. Plant polyphenols, carotenoids, dietary fiber (in Polish). Probl. Hig. Epidemiol., 94: 41-49.

Zhang H.J., Jiang X.R., Mantovani G., Valdez Lumbreras A.E., Comi M., A 1 bora1i G., S a v o in i G., D e 11' O r t o V., B o n t e m p o V. (2014). Modulation of plasma antioxidant activity in weaned piglets by plant polyphenols. Ital. J. Anim. Sci., 13: 32-42.

Zhang X., Zha o L., Ca o F., A hmad H., Wang G., Wang T. (2013). Effects of feeding fermented Ginkgo biloba leaves on small intestinal morphology, absorption, and immunomodulation of early lipopolysaccharide-challenged chicks. Poultry Sci., 92: 119-130.

Z h o n g R., Z h o u D. (2013). Oxidative stress and role of natural plant derived antioxidants in animal reproduction. J. Integr. Agr., 12: 1826-1838.

Zhu C., Wu Y., Ji ang Z., Z heng C., Wang L., Yang X., Hu Y. (2015). Dietary soy isoflavone attenuated growth performance and intestinal barrier functions in weaned piglets challenged with lipopolysaccharide. Int. Immunopharmacol., 28: 288-294.

Received: 20 XI 2015

Accepted: 13 VI 2016 